\title{
Clinical signs, diagnosis and treatment of three dogs with angiostrongylosis in Ireland
}

\author{
Sheila F. Brennan ${ }^{1}$, Grainne McCarthy ${ }^{1}$, Hester McAllister ${ }^{2}$, Hugh Bassett ${ }^{3}$ and Boyd R. Jones ${ }^{1}$ \\ Departments of ${ }^{1}$ Small Animal Clinical Studies, ${ }^{2}$ Veterinary Surgery and ${ }^{3}$ Veterinary Pathology, \\ Faculty of Veterinary Medicine, University College Dublin, Belfield, Dublin 4, Ireland.
}

Infection with Angiostrongylus vasorum was diagnosed at necropsy on a dog that died from acute pulmonary haemorrhage, and on recovery of L1 larvae by Baermann examination of faeces from two dogs, one of which had abdominal pain and retroperitoneal haemorrhage, while the other had right-sided heart failure due to cor pulmonale. The presenting signs included syncope (one dog), exercise intolerance (two dogs), cough (two dogs), abdominal pain (one dog) and depression (one dog). One-

\section{Key words}

Dog,

Angiostrongylus vasorum, Clinical signs,

Diagnosis,

Treatment. stage prothrombin time and activated partial thromboplastin time were prolonged in two dogs, buccal mucosal bleeding time was prolonged in one dog and globulin was elevated in all three dogs. Two dogs were treated with fenbendazole and recovered.

Irish Veterinary Journal

Volume 57: $103-109,2004$

\section{Introduction}

Angiostrongylus vasorum, a metastrongylid nematode which parasitises domestic dogs and other Canidae, has an indirect lifecycle requiring gastropods (snails, slugs) as intermediate hosts (Bolt et al., 1994). A. vasorum infection has been reported in many countries including France, Italy, Spain, Denmark, Wales, England, Ireland, Uganda and Brazil (Martin and Neal, 1992). The first reported case of A. vasorum infection in Ireland was in a greyhound (Roche and Kelliher, 1968) and the first recorded case from Britain was a greyhound imported from Ireland (Jacobs and Prole, 1975).

The adult worms parasitise the right side of the heart and the pulmonary arteries (Figure 1). Eggs released from the adult female are transported to the pulmonary capillaries where they hatch. The first stage Ll larvae penetrate the capillary and alveolar walls to enter the airway, from where they are coughed into the pharynx and swallowed. They are excreted in faeces and

Correspondence:

\section{Sheila F. Brennan}

Department of Small Animal Clinical Studies,

Faculty of Veterinary Medicine,

University College Dublin,

Belfield, Dublin 4,

IRELAND.

Tel: +35317166012

Fax: +3531716 6023

E-mail: sheila.brennan@ucd.ie

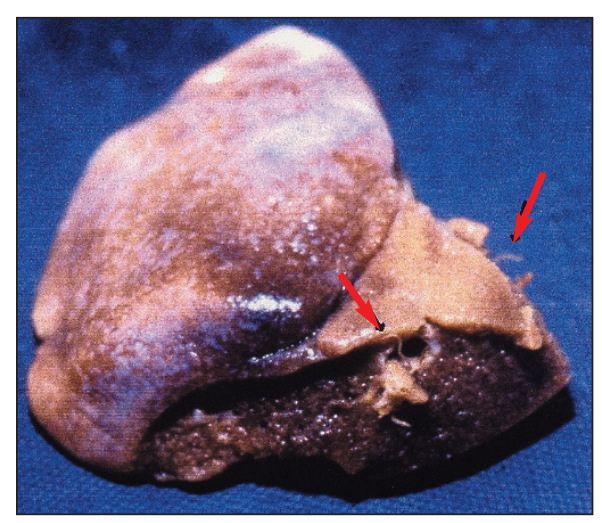

FIGURE I: Adult Angiostrongylus vasorum (arrows) within pulmonary vessels of formalinfixed lung.

the intermediate hosts (slugs and snails) ingest the larvae whilst foraging in the faeces. Bolt et al. (1994) showed that the common frog (Rana temporaria) might act as a paratenic and also as an intermediate host for $A$. vasorum. Whilst in the intermediate host the larvae develop to the L3 stage. The canine host is infected when it ingests the L3 larvae. Once ingested, L3 larvae penetrate the walls of the gastrointestinal tract (Bolt et al., 1994) and invade the mesenteric, portal and caecocolic lymph nodes where they develop to the L5 larval stage (Rosen et al., 1970). From the lymph nodes, migration to the right heart and pulmonary arteries occurs via the hepatic portal vein, liver and caudal vena cava (Bolt et al., 1994). This final migration and maturation to adulthood takes approximately 10 days to complete (Rosen et al., 1970). The prepatent period is approximately 38 to 57 days (Bolt et al., 1994). 


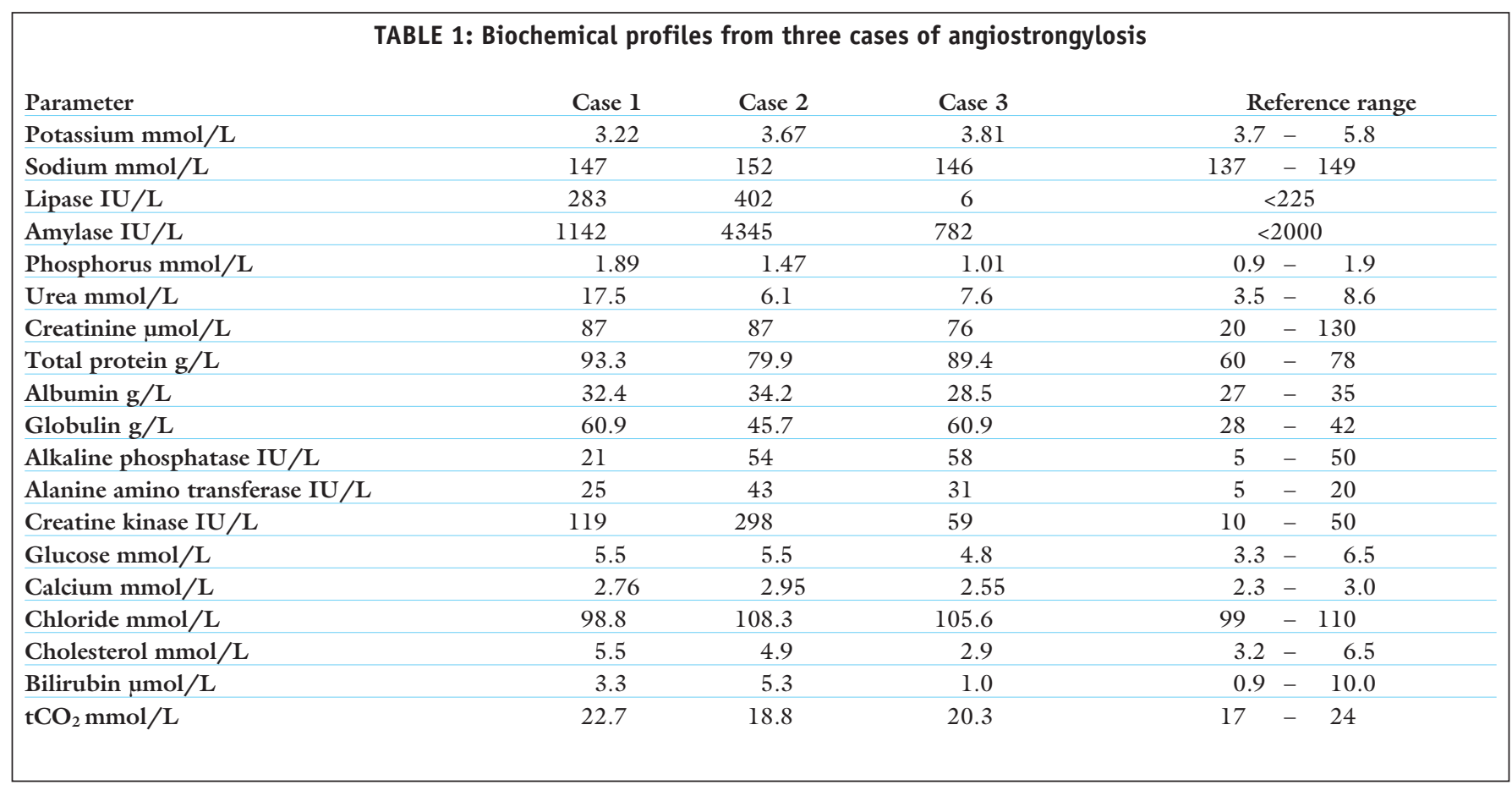

This paper presents the clinical signs, diagnosis, treatment and outcome of three dogs with $A$. vasorum infection referred to the University Veterinary Hospital (UVH) of the Faculty of Veterinary Medicine, University College Dublin during $2001 / 2002$.

\section{Case 1}

A 20-month-old male Cavalier King Charles spaniel, from a suburban coastal village near Dublin, was referred with a fiveday history of depression, cough and tachypnoea. He was unable to walk for any distance due to respiratory distress. The owners had observed weight loss and had noted coughing for the first time three weeks previously. The full brother and housemate of this dog had died five days prior to the referral with similar clinical signs and one episode of haemoptysis. Both dogs were vaccinated and had been treated with praziquantel, pyrantel embonate and febantel (Drontal Plus, Bayer). There was no history of trauma or of access to rodenticides or pesticides.

The dog had been treated with $2 \mathrm{mg} / \mathrm{kg}$ vitamin Kl (Konakion, Roche) and marbofloxacin (Marbocyl, Vétoquinol) for three days prior to referral, as anticoagulant rodenticide poisoning was suspected, but there had been no improvement.

On clinical examination, he was in poor body condition (weight $8 \mathrm{~kg}$ ), depressed and tachypnoeic. Lung sounds were audible throughout the lung fields. Mucous membranes were pale but mucosal or submucosal haemorrhages were not seen and the capillary refill time was normal ( $<2$ seconds). The rectal temperature was $38.9^{\circ} \mathrm{C}$.

Routine haematology, a biochemical profile, one-stage prothrombin time (OSPT) and activated partial thromboplastin

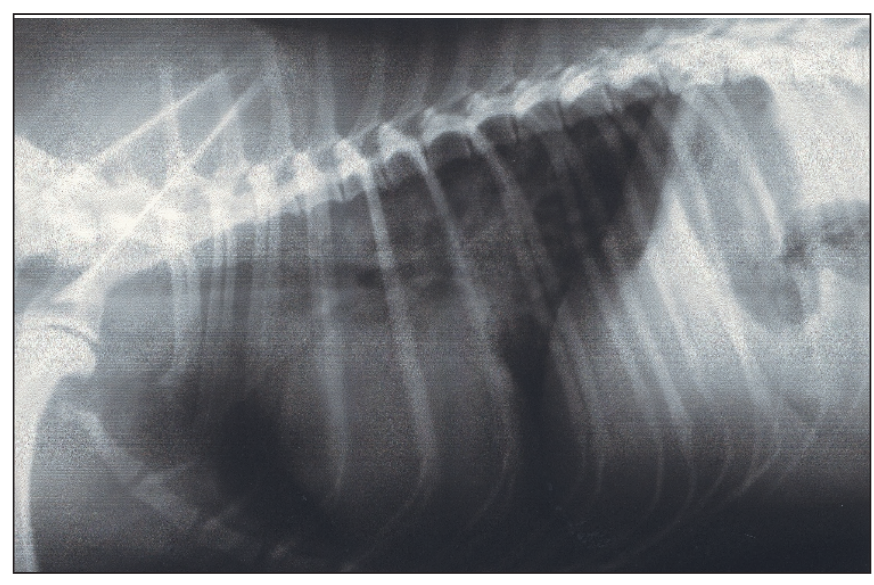

FIGURE 2: Right lateral recumbent radiograph illustrating a marked alveolar perihilar infiltrate. The dog (case I) died five hours later.

time (APTT) were carried out (Tables 1 and 2). Buccal mucosal bleeding time (BMBT) was measured using the Simplate R device (Organon Teknika Corp., USA) and the wound was still bleeding after 10 minutes. When bleeding did cease, a submucosal haematoma formed at the incision site. Lateral (Figure 2) and dorsoventral thoracic radiographs showed a widespread patchy alveolar and interstitial infiltrate in all lung lobes.

Anticoagulant rodenticide poisoning was still suspected based on the prolonged OSPT, APTT, prolonged BMBT and adequate platelet numbers. Fresh frozen plasma was administered at $20 \mathrm{ml} / \mathrm{kg}$ and given over 1.5 hours and $5 \mathrm{mg} / \mathrm{kg}$ of vitamin $\mathrm{Kl}$ was administered per os. 


\section{peer reviewed}

\begin{tabular}{|c|c|c|c|c|c|c|}
\hline \multirow[b]{2}{*}{ Packed cell volume $\mathrm{L} / \mathrm{L}$} & \multirow{2}{*}{$\begin{array}{r}\text { Case } 1 \\
0.37\end{array}$} & \multirow{2}{*}{$\begin{array}{r}\text { Case } 2 \\
0.44\end{array}$} & \multirow{2}{*}{$\begin{array}{r}\text { Case } 3 \\
0.35\end{array}$} & \multicolumn{3}{|c|}{ Reference range } \\
\hline & & & & 0.37 & - & 0.55 \\
\hline Haemoglobin $\mathrm{g} / \mathrm{L}$ & 118 & 151 & 146 & 120 & - & 180 \\
\hline Red blood cell count $\times 10^{12} / \mathrm{L}$ & 5.1 & 6.2 & 4.7 & 5.5 & - & 8.5 \\
\hline $\mathrm{MCHC} \mathrm{g} / \mathrm{L}$ & 316 & 341 & 417 & 320 & - & 360 \\
\hline $\mathrm{MCV} \mathrm{fl}$ & 73.0 & 71.0 & 74.0 & 60 & - & 77 \\
\hline $\mathrm{MCH}$ pg & 23.0 & 24.4 & 31.3 & 19 & - & 25 \\
\hline Platelets $\times 10^{9} / \mathrm{L}$ & $7.0^{*}$ & 116.0 & 619 & 200 & - & 500 \\
\hline Plasma protein $\mathrm{g} / \mathrm{L}$ & 102 & 74.0 & 88.0 & 58 & - & \\
\hline White blood cell count $\times 10^{9} / \mathrm{L}$ & 55.2 & 18.4 & 20.9 & 7 & - & 17 \\
\hline Neutrophils (mature) $\times 10^{9} / \mathrm{L}$ & 39.7 & 16.7 & 15.6 & 3 & - & 11.5 \\
\hline Neutrophils (band) $\times 10^{9} / \mathrm{L}$ & 7.1 & 0 & 0 & 0 & - & 0.6 \\
\hline Lymphocytes $\times 10^{9} / \mathrm{L}$ & 4.4 & 0.7 & 2.2 & 1 & - & 4.8 \\
\hline Monocytes x $10^{9} / \mathrm{L}$ & 0.5 & 0.9 & 2.5 & 0.2 & - & 1.3 \\
\hline Eosinophils $\times 10^{9} / \mathrm{L}$ & 0 & 0 & 0.4 & 0 & - & 1.3 \\
\hline Basophils $\times 10^{9} / \mathrm{L}$ & 0.3 & 0 & 0 & 0 & - & 0 \\
\hline Nucleated red blood cells $\times 10^{9} / \mathrm{L}$ & 2.7 & 0 & 0 & 0 & - & 0 \\
\hline One-stage prothrombin time (seconds) & 18.2 & 9.8 & not performed & 6 & - & 12 seconds \\
\hline Activated partial thromboplastin time (seconds) & 26.1 & 14.2 & not performed & 14 & - & 24 seconds \\
\hline
\end{tabular}

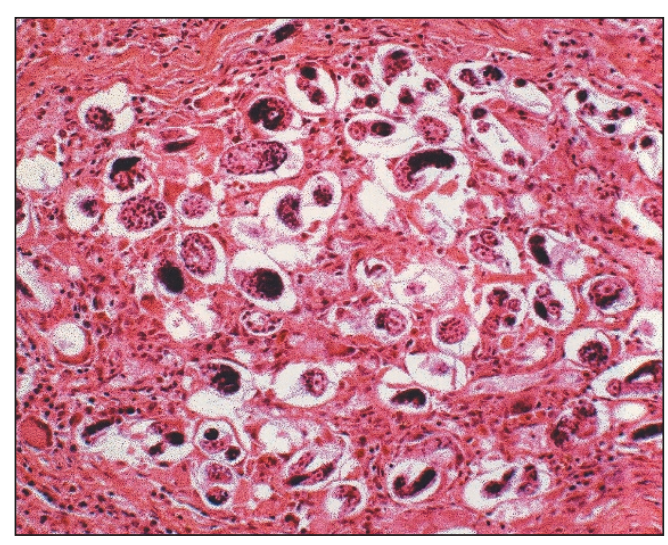

FIGURE 3:

Eggs and larvae within alveoli. Original magnification: I0x, H\&E.

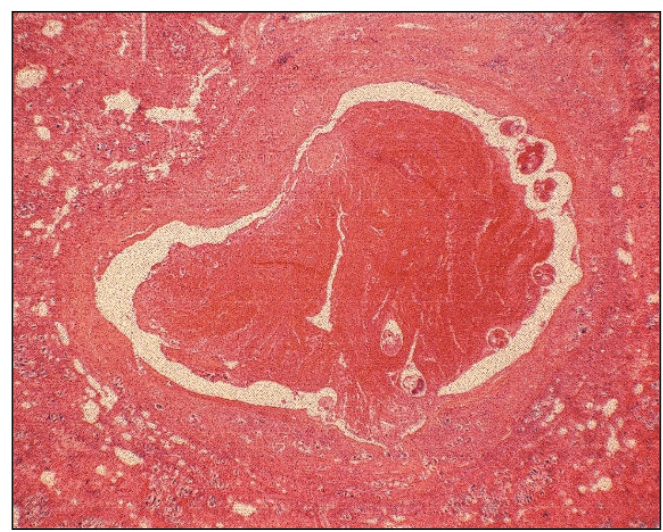

FIGURE 4:

Pulmonary thrombus adult worms, $\mathrm{H} \& \mathrm{E}$.
After the plasma transfusion the respiratory rate increased, the mucous membranes became paler, the packed cell volume fell to $0.31 \mathrm{~L} / \mathrm{L}$. Oxygen was insufflated through an intranasal tube at $1 \mathrm{~L} /$ minute. Fluid therapy was continued with compound sodium lactate at $5 \mathrm{ml} / \mathrm{kg} / \mathrm{h}$. One hour after nasal oxygen administration commenced the dog stood, coughed up a large volume of blood and died despite attempted resuscitation: intubation, ventilation, cardiac massage and intravenous adrenaline administration.

At necropsy an extensive area of subcutaneous haemorrhage extended over the right side of the neck, this was likely due to haemorrhage at time of venepuncture. Extensive pulmonary consolidation was apparent throughout all of the lung lobes. There was right-sided cardiomegaly associated with dilation of the right ventricle, the pulmonary artery appeared unaffected. Other macroscopic changes noted included hepatomegaly, small blood clots in the tracheal lumen and contracted spleen. Examination of a longitudinal section cut through the left femur revealed that the medulla was filled exclusively with red marrow. Worms were not seen in the right heart or the pulmonary artery. associated with
Histopathologically, extensive areas of interstitial pneumonia were associated with large numbers of parasite eggs and larvae (Figure 3). Haemosiderin-laden macrophages were seen within the alveoli in affected areas. Adult worms associated with large thrombi were apparent within one of the large arteries (Figure 4). A diagnosis of verminous pneumonia associated with $A$. vasorum was made. It is likely that the brother of this dog also died from infection associated with $A$. vasorum due to the similar clinical features as described by the referring veterinary surgeon. 


\section{Case 2}

A 17-month-old female greyhound was referred to the UVH with a history of two episodes of abdominal distension and pain after exercise. She had been vaccinated and treated with praziquantel, pyrantel embonate and febantel (Drontal Plus, Bayer) every two months before examination. She was one of a number of kenneled greyhounds from a racing kennel on the west coast of Ireland and had been in the owner's possession for three months.

On examination, she was quiet. Heart rate was 96 beats per minute with a sinus rhythm. The dog was in good body condition, weighing $31.1 \mathrm{~kg}$. Rectal temperature was $39.2^{\circ} \mathrm{C}$. Her abdomen was tense and abnormalities were not palpated.

Routine haematology, a biochemical profile, OPST and APTT were carried out. Faeces was collected for parasitological examination and urine for urinalysis. Blood results are shown in Tables 1 and 2. The urine was dark red/black in colour, which was attributed to haemoglobin and not to myoglobin. Faecal analysis recovered $A$. vasorum larvae, Capillaria spp. eggs and Uncinaria stenocephala eggs. Abdominal radiographs were taken and abdominal ultrasonography was performed. The abdominal radiographs showed marked ventral displacement of the colon by a soft tissue opacity in the caudal abdomen, ventral to the sublumbar muscle mass (Figure 5). Ultrasonography identified a linear, hypoechoic, septated, lobulated mass, $14 \mathrm{~cm}$ long and 8 to $10 \mathrm{~cm}$ wide, dorsal to the bladder and extending cranially to the caudal pole of the left kidney. The characteristics of the mass were consistent with an organising haematoma or similar haemorrhagic tissue within the retroperitoneum. Four days later, the abdomen was re-examined by both ultrasonography and radiography. The colon had returned to a normal position (Figure 6), but the hypoechoic mass was still present with anechoic areas present within it, consistent with the appearance of an organising haematoma. Thoracic radiographs showed widespread interstitial infiltration throughout the lung fields and the cardiac axis was shifted to the left on the ventrodorsal view suggesting right-sided cardiac enlargement (Figure 7). Echocardiography was not performed.

The dog was diagnosed with retroperitoneal and urinary tract haemorrhage, right-sided cardiac enlargement and verminous pneumonia as a result of infection with $A$. vasorum. Haemorrhage in the retroperitoneal space may have resulted from trauma to the iliopsoas muscle during exercise. Fifty $\mathrm{mg} / \mathrm{kg}$ of fenbendazole (Panacur, Intervet) was administered daily for five days and the dog was discharged. There have been no further episodes of abdominal pain.

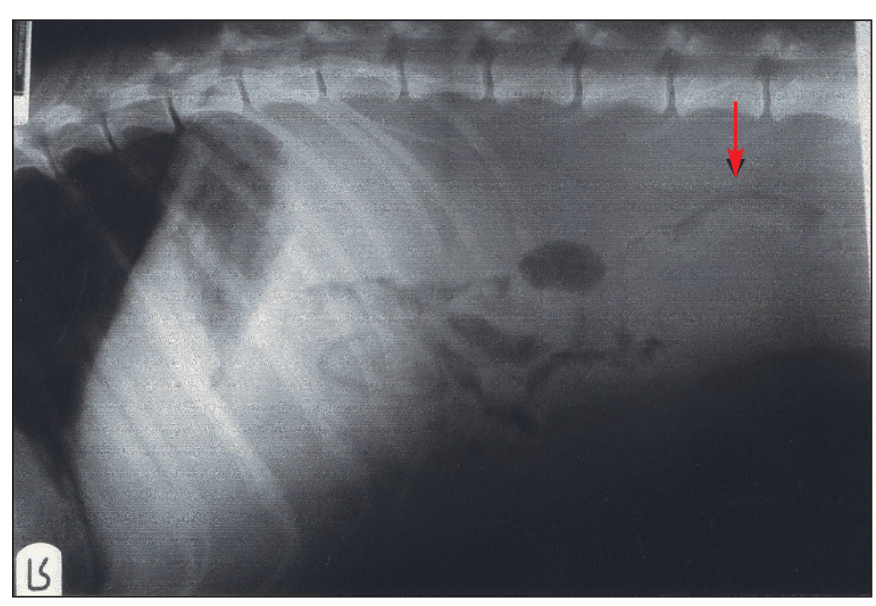

FIGURE 5: Ventral depression of the colon (arrow) by a retroperitoneal soft tissue opacity, ventral to L3-L6.

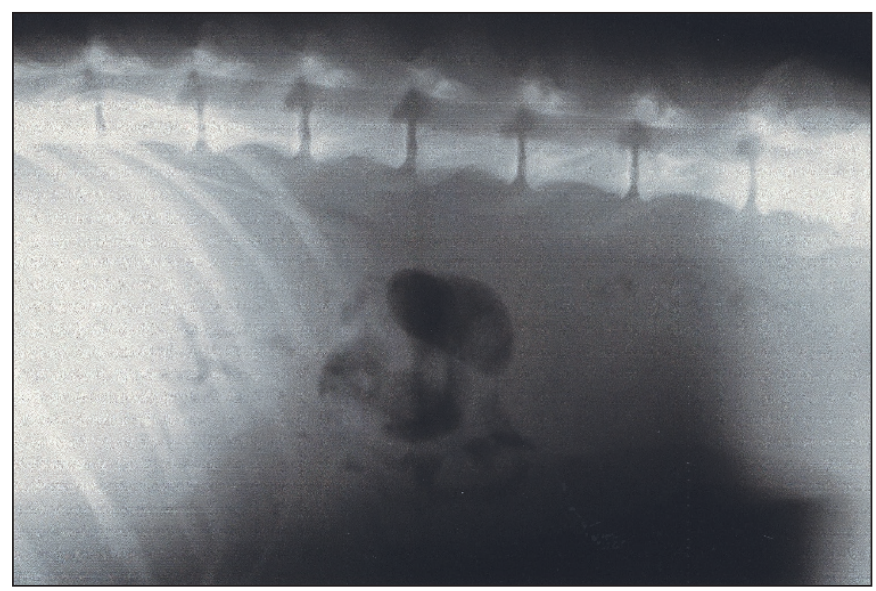

FIGURE 6: Post-treatment radiograph taken five days after Figure 5, showing the colon in a normal position.

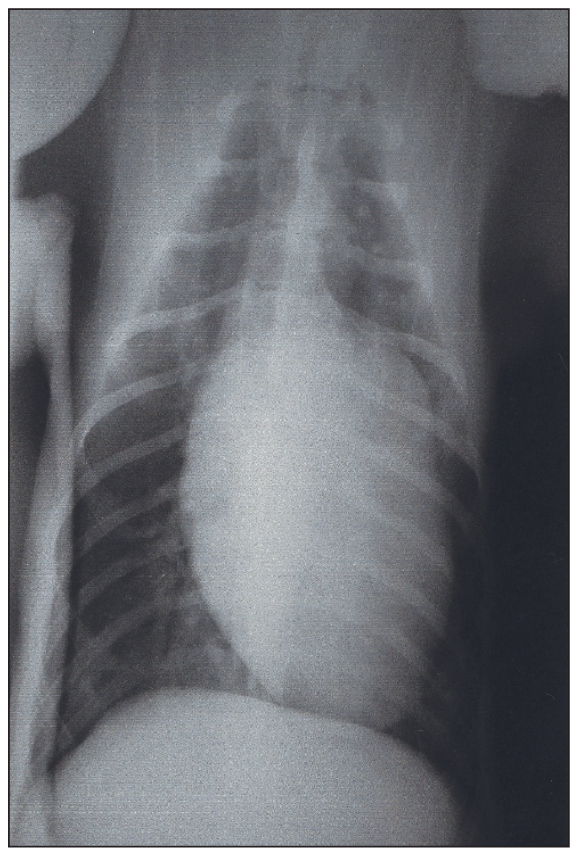

FIGURE 7:

Widespread interstital pulmonary pattern particularly in the right caudal area. There is a shift of the apex of the heart to the right-hand side suggesting right ventricular enlargement. 


\section{Case 3}

A 23-month-old male Jack Russell terrier was referred for investigation of syncope. The dog had been bred in Wales but lived in Co Wicklow for most of its life. Its history of treatment for worms was unknown, but it had been vaccinated. The dog had reduced exercise tolerance and intermittent cough over the last two months and three episodes of syncope in the preceding week.

On examination, the dog was very bright and alert. The heart rate was elevated (192 beats per minute) and bilateral jugular pulses were present above the level of the thoracic inlet. The respiratory rate was increased ( 88 breaths per minute) and bronchial sounds were harsh. Mucous membranes were pale and capillary refill time was normal ( $<2$ seconds).

Blood was collected for haematology and a biochemical profile (see Table 1 and 2). Thoracic radiographs, thoracic ultrasonography and an electrocardiogram (ECG) were performed. There was a generalised bronchial-interstitial infiltrate in all the lung lobes, right-sided cardiac enlargement and enlargement of the main pulmonary artery segment. Echocardiography confirmed severe right ventricular, right atrial and pulmonary artery dilation. The ECG was normal. Baermann examination (Urquhart et al., 1996) of faeces recovered Angiostrongylus vasorum larvae. Both the cardiac enlargement and pulmonary changes were attributed to $A$. vasorum infection. Verminous pneumonia and resultant cor pulmonale were diagnosed. The dog was hospitalised for treatment with fenbendazole (Panacur, Intervet) at a dose of $50 \mathrm{mg} / \mathrm{kg}$ per os for seven days. Prednisolone was administered starting two days prior to fenbendazole therapy at $1 \mathrm{mg} / \mathrm{kg}$ q $24 \mathrm{~h}$ to avoid potential anaphylaxis (Bolt et al., 1994). Treatment with benazapril (Fortekor, Novartis) at $0.25 \mathrm{mg} / \mathrm{kg}$ q $24 \mathrm{~h}$ was begun at this time and two months later theophylline (Corvental-D, Vericore) at $20 \mathrm{mg} / \mathrm{kg}$ q $24 \mathrm{~h}$ was administered as episodes of syncope continued to occur every two weeks. Follow-up cardiac ultrasonographic examinations have shown progressive reduction in size of the right atrium and ventricle. Syncope has not occurred since theophylline was administered and larvae were not seen on a repeat Baermann examination of faeces two months after treatment with fenbendazole.

\section{Discussion}

The majority of dogs with angiostrongylosis reported in the literature have been young (Martin et al., 1993) and our cases were less than two years of age (17 to 23 months old). Dogs with angiostrongylosis have histories varying from racing greyhounds with poor performance and multiple haematomata (Dodd, 1973) to pet dogs with hind limb paralysis (Martin et al., 1993). However, the most common clinical signs reported have been coughing, dyspnoea and exercise intolerance (Ramsey et al., 1996). Other clinical signs observed include sudden death (King et al., 1994), weight loss, vomiting, abdominal pain, syncope, neurological signs, hind-limb rigidity, hind-limb paralysis, lumbar pain (Martin et al., 1993), coagulopathy (disseminated intravascular coagulation: DIC; Ramsey et al., 1996) and thrombocytopenia (Gould and McInnes, 1999). The dogs in this study had some of the above signs including cough, syncope and sudden death but retroperitoneal haemorrhage seen in case 2 had not been reported previously.

Signs of bleeding were present in two dogs (cases 1 and 2) and anticoagulant rodenticide poisoning was considered the most likely diagnosis based on prolonged OSPT and APTT. However, the poor response to vitamin $\mathrm{Kl}$ in case $\mathrm{l}$ and the chronic nature of the signs in case 2 suggested another aetiology. The cause of the coagulopathy associated with angiostrongylosis has not been fully defined but antigenic stimulation resulting in chronic DIC has been proposed as a possible mechanism (Schelling et al., 1986; Ramsey et al., 1996). Schelling et al. (1986) experimentally infected l6-weekold cross-bred dogs and found thrombocytopenia, prolonged APTT and, eventually, prolonged OSPT. Fibrin degradation products (FDP) remained normal in the experimentally infected animals but were present in a naturally infected dog described by Ramsey et al. (1996). FDPs were not measured in any of the dogs of this report. Thrombocytopenia was present in case 2 and OSPT and APTT were abnormal in cases 1 and 2 and at necropsy extensive subcutaneous haemorrhage was present on the right side of the neck in case 1. In Ireland, angiostrongylosis should be considered as a differential diagnosis for any dog with spontaneous bleeding or haemorrhage even when APTT, OSPT, FDPs and thrombocyte numbers are within the reference range.

Packed cell volume (PCV) was within the reference range for case $1(0.37 \mathrm{~L} / \mathrm{L}$, reference range 0.37 to $0.55 \mathrm{~L} / \mathrm{L})$, slightly below the reference range in case $3(0.35 \mathrm{~L} / \mathrm{L})$ and below the greyhound reference range for case 2 ( PCV $0.44 \mathrm{~L} / \mathrm{L}$, greyhound reference range 0.55 to $0.65 \mathrm{~L} / \mathrm{L}$; Holloway, 1998). There was significant evidence of regeneration present in case 1 in the form of nucleated red blood cells and red marrow present within the left femur at necropsy. All dogs had a raised total protein, especially the globulin fraction in cases 1 and 3 . Hyperglobulinaemia has been previously reported in infected dogs (Perry et al, 1991; Patteson et al., 1993); the cause is unclear but may be due to antigenic stimulation. Whilst eosinophilia was a finding elsewhere (Patteson et al., 1993) eosinophil counts were within reference range in our dogs. Raised urea in case 1 was most likely due to ingestion and digestion of blood. Pathognomonic haematological or biochemical findings that would aid in the diagnosis of angiostrongylosis, have not been reported.

Radiological changes in experimentally infected dogs were described by Mahaffey et al. (1981) and there have been case reports that included radiological findings (Dodd, 1973; Cobb and Fisher, 1990; Patteson et al., 1993; Ramsey et al., 1996; Gould and McInnes, 1999). The most notable radiological feature is a diffuse interstitial pulmonary infiltrate with transient 
alveolar pattern. All three dogs in this report were radiographed and had interstitial infiltrates and cases 2 and 3 had right-sided cardiac enlargement. Dogs experimentally infected with $A$. vasorum developed interstitial pneumonia (with eosinophil, neutrophil, plasma cell and foreign body giant cell reactions forming small granulomata) and intimal fibrosis of the pulmonary vessels (Prestwood et al., 1981). This inflammatory process resulted in expansion of the tissue surrounding the pulmonary arteries causing interstitial pneumonia and an interstitial pulmonary pattern radiographically. Histopathological evidence of interstitial pneumonia in case 1 concurs with the experimental findings. Haemorrhage and granulomas were noted (alveolar pattern) early in the experimentally infected dogs and, as the disease became more chronic, pleural and parenchymal lung fibrosis occurred. Rightsided cardiac failure which occurred in case 3 can result from pulmonary parenchymal fibrosis and the cardiomegaly seen in case 1 at necropsy examination may have a similar aetiology.

The definitive diagnosis of angiostrongylosis is based on the demonstration of Ll larvae (Figure 8), with their distinctive cephalic button, tail appendage and dorsal notch, in faeces or fluid from the respiratory tract (Bolt et al., 1994). The Baermann technique is the best method to recover Ll larvae and it is important to remember that larvae are not excreted continuously; therefore, false negative results occur (Bolt et al., 1994) and repeated faecal examination may be necessary. Other metastrongylid larvae present in faeces include Crenosoma vulpis larvae; however, the tip of the tail is straight and pointed, unlike the typical notch followed by constriction and terminal lance like point of $A$. vasorum (McGarry et al., 1995). Currently, a blood-based diagnostic test is not available for occult cases of $A$. vasorum infection.

A number of different treatments have been recommended; each credited with varying success. Levamisole $(7.5 \mathrm{mg} / \mathrm{kg} \mathrm{s} / \mathrm{c}$ q24h for two days, then $10 \mathrm{mg} / \mathrm{kg} \mathrm{s} / \mathrm{c} \mathrm{q} 24 \mathrm{~h}$ for two days) is effective in killing adult worms quickly. However, dogs are at greater risk of anaphylaxis due to release of worm antigens following rapid killing of worms and it is recommended to treat with corticosteroids concurrently (Søland and Bolt, 1996). Ivermectin $(0.2 \mathrm{mg} / \mathrm{kg}$ subcutaneously twice with a seven-day interval) has been used with success (Martin et al., 1993), but ivermectin is an unlicensed product and it can cross the blood brain barrier in collie-type dogs and may result in neurological signs. Benzimidazoles have been reported to have good success and fenbendazole can be administered at different doses for varying periods (i.e., $20 \mathrm{mg} / \mathrm{kg}$ q $24 \mathrm{~h}$ up to $100 \mathrm{mg} / \mathrm{kg}$ q $24 \mathrm{~h}$ for seven to 21 days; Martin et al., 1993; Bolt et al., 1994), case 2 and 3 were managed by different clinicians and received varying treatment regimens due to this wide variation in the literature. Benzimidazoles and ivermectin certainly result in zero faecal larval counts, but it is not known if they are adulticidal (Bolt $e t$ al., 1994). Cases 2 and 3 in this report improved after treatment with fenbendazole and larvae were not recovered by

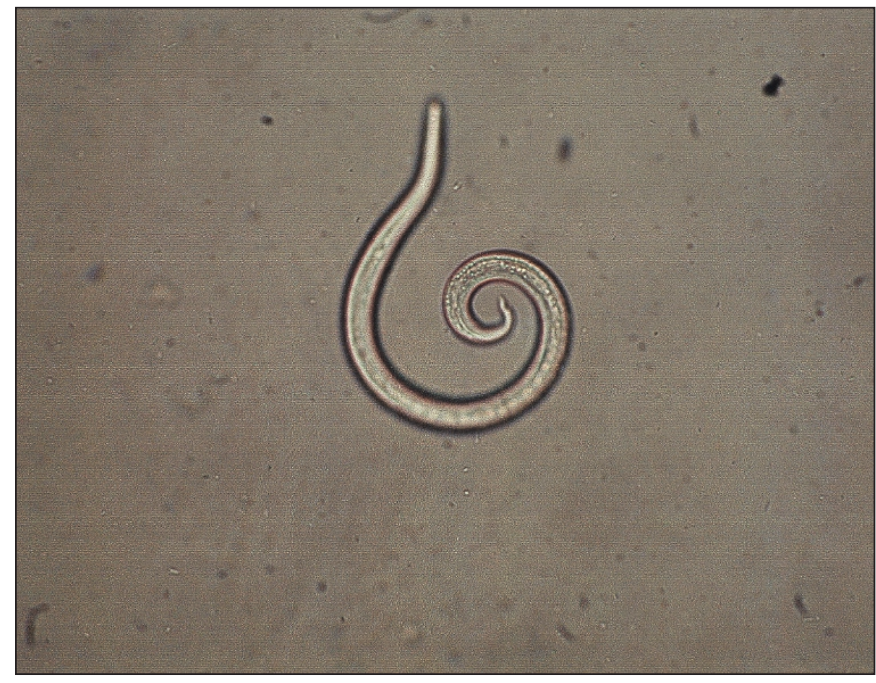

FIGURE 8: Angiostrongylus vasorum LI larva.

Baermann examination in case 3 eight weeks after treatment. There are no published data on the efficacy of the praziquantel, pyrantel embonate and febantel (Drontal Plus, Bayer) combination against Angiostrongylus spp.

$A$. vasorum infection is a potential threat to dogs in endemic areas even if they receive regular anthelmintic therapy. Clinical signs of angiostrongylosis are varied and diagnosis can be difficult unless the condition is suspected and radiographs and Baermann examination are performed but, even in infected dogs, Baermann examination may be negative. More work is required to quantify and fully understand the bleeding abnormalities in clinical cases. Commonly used anthelmintics may be inappropriate to treat $A$. vasorum infection; therefore, treatment with drugs that are efficacious against Angiostrongylus spp. may be indicated and multi-anthelmintic regimens need to be investigated. Climactic conditions might influence prevalence. Many months in 2002 were milder and wetter with higher soil temperatures as compared with the year 2001 and with the 30-year mean values from 1961 to 1990 (Met Eireann, www.met.ie); thus, intermediate host numbers may be higher. The prevalence of $A$. vasorum infection in dogs in Ireland is unknown and it could be more prevalent and important than is currently recognised. Furthermore, there is a need for an accurate serological diagnostic test to complement the Baermann technique for the diagnosis of occult infection.

\section{Acknowledgements}

We thank the veterinary surgeons who referred these cases. The assistance of the veterinary nurses, veterinary students, laboratory and technical staff and colleagues at the UVH is appreciated and valued. 


\section{References}

Bolt, G., Monrad, J., Koch, J. and Jensen, A.L. (1994). Canine angiostrongylosis: a review. Veterinary Record 135: 447-452.

Cobb, M.A. and Fisher, M.A. (1990). Angiostrongylus vasorum: Transmission in south-east England. Veterinary Record 126: 529.

Dodd, K. (1973). Angiostrongylus vasorum (Baillet, 1866) infestation in a greyhound kennels. Veterinary Record 92: 195-197.

Gould, S.M. and McInnes, E.L. (1999). Immune-mediated thrombocytopenia associated with Angiostrongylus vasorum infection in a dog. Journal of Small Animal Practice 40: 227-232.

Holloway, S.A. (1998). Stress- and performance- related illness in sporting dogs. In: Canine Sports Medicine and Surgery. Edited by M.S. Bloomberg, J.F. Dee and R.A. Taylor. Philadelphia: Saunders. p33.

Jacobs, D.E. and Prole, J.H.B. (1975). Angiostrongylus vasorum and other nematodes in British greyhounds. Veterinary Record 96: 180.

King, M.C.A., Grose, R.M.R. and Startup, G. (1994). Angiostrongylus vasorum in the anterior chamber of a dog's eye. Journal of Small Animal Practice 35: 326-328.

Mahaffey, M.B., Losonsky, J.M., Prestwood, A.K., Mahaffey, E.A. and Lewis, R.E. (1981). Experimental canine angiostrongylosis: II. Radiographic manifestations. Journal of the American Animal Hospital Association 17: 499-502.

Martin, M.W.S. and Neal, C. (1992). Distribution of angiostrongylosis in Cornwall. Journal of Small Animal Practice 33: 327-330.

Martin, M.W.S., Ashton, G., Simpson, V.R. and Neal, C. (1993). Angiostrongylosis in Cornwall: Clinical presentation of eight cases. Journal of Small Animal Practice 34: 20-25.

McGarry, J.W., Martin, M., Cheeseman, M.T. and Payne-Johnson, C.E. (1995). Crenosoma vulpis, the fox lungworm, in dogs. Veterinary Record 137: 271-272.

Patteson, M.W., Gibbs, C., Wotton, P.R. and Day, M.J. (1993). Angiostrongylus vasorum infection in seven dogs. Veterinary Record 133: 565-570.

Perry, A.W., Hertling, R. and Kennedy, M.J. (1991). Angiostrongylosis with disseminated larval infection associated with signs of ocular and nervous disease in an imported dog. Canadian Veterinary Journal 32: 430-431.

Prestwood, A.K., Greene, C.E., Mahaffey, E.A. and Burgess, D.E. (1981). Experimental canine angiostrongylosis: I. Pathologic manifestations. Journal of the American Animal Hospital Association 17: 491-497.

Ramsey I.K., Littlewood, J.D., Dunn, J.K. and Herrtage, M.E. (1996). Role of chronic disseminated intravascular coagulation in a case of canine angiostrongylosis. Veterinary Record 138: 360-363.

Roche, M.M. and Kelliher, D.J. (1968). Angiostrongylus vasorum infestation in the dog: A case report. Irish Veterinary Journal 22: 108-113.

Rosen, L., Lawrence, R. and Wallace, G. (1970). Life history of the canine lungworm Angiostrongylus vasorum (Baillet). American Journal of Veterinary Research 31: 131-143.

Schelling, C.G., Greene, C.E., Prestwood, A.K. and Tsang, V.C.W.
(1986). Coagulation abnormalities associated with acute Angiostrongylus vasorum infection in dogs. American Journal of Veterinary Research 47: 2669-2673.

Søland, J. and Bolt, G. (1996). Hypovolaemic shock after anthelmintic treatment of canine angiostrongylosis. Journal of Small Animal Practice 37: 594-596.

Urquhart, G.M., Armour, J., Duncan, J.L., Dunn, A.M. and Jennings, F.W. (1996). Veterinary Parasitology. Second edition, pp 277-278. Oxford: Blackwell Science. 